Antun Foškulo

Končar - Power Plant and Electric Traction Engineering Inc. Croatia

\section{Mario Kokoruš}

entegra eyrich + appel $\mathrm{GmbH}$

Germany

\title{
Contractors as modern Master Builders: Virtual Design and Construction as an enabler of meaningful experiences to project teams for achieving optimized substation management
}

\section{SUMMARY}

Effective substation management should include engineering and construction costs. While the construction process has to be methodically planned and sequenced to achieve optimized construction costs, substation designers play a vital role for delivering cost-efficient substations. Integrated design and construction has been proposed as a way to achieve effective project management, which historically viewed, was a responsibility of a "master builder", thus causing Contractors to identify themselves as "master builders".

As EPC is a highly competitive arena, Contractors are looking for ways to differentiate themselves from their competitors. Some are turning to 3D technologies, while others turn to the design-construction integration. Virtual Master Builder (VMB) supports both 3D technologies and the designconstruction integration. Due to a global shortage of worldwide available expertise, Contractors turn to education and training of their employees. While education aims at providing basic skills, training aims to provide the skill necessary to do the job. This paper examines these basic skills as a part of personal mastery before defining organizational learning as a key organizational competence.

Physical Virtuality realm is seen as a fruitful ground for staging of memorable and transformational experiences leading towards achieving "accelerated learning", and especially 4D models as representations of a "space-time" environment. The project case of Skopje 4 SS 380/110 kV rehabilitation is given as an example of $4 \mathrm{D}$ models usage. Project Engineering is seen as a middle ground between engineering and management in order to achieve goals of effective substation management and cost-efficient substation solutions. Project teams are seen as Virtual Design and Construction (VDC) users to achieve these goals.

\section{KEYWORDS}

Virtual Design and Construction - Master Builder - Contractor - Substation - Experience - Differentiation - Project team - Project Engineering - Learning - Integration 


\section{INTRODUCTION}

Ever since the war of currents started, the race to electrify the world has been accelerating [1]. In 2013, the power sector was reported to be a new dominant sector [2]. In a survey, 77 percent of respondents reported underperforming projects due to various causes, but mainly due to project delays, poor estimating practices and failed risk management processes [2].

Effective substation management, as it was warned, should include al relevant cost factors [3], while engineering and construction costs should be included under the cost of acquisition [4]. As according to [5], the cost reduction of Air Insulated Substations (AIS) should focus on minimizing the construction time and on eliminating mis-sequencing of construction activities, due to negative forces reported such as a shorter civil construction period to build a new substation, and a requirement for a short installation period. For this, a remedy is advised by means of standardizing both design and construction processes and methods [5]. In order to optimize substation costs, attention should be paid on having accurate and detailed engineering and on having experienced and well-trained construction crews, among others [5]. Generally, for risks related to overexpenditures and delays due to miscoordination at site, mitigation in the form of making schedules of manpower and heavy equipment is advised alongside advising monitoring and adjusting time schedules accordingly [6]. Essentially, construction processes have to be methodically planned and sequenced to achieve optimization of construction costs [5]. However, planning the installation of the substation equipment and sequencing it require experience and specialized knowledge [7]. Even though an effective cost and schedule control system is acknowledged to be of a paramount importance for delivering substation construction projects on time and within the budget [8], it has been found out that scheduling, definition of resources and tracking are the least practiced project considerations [9]. Indeed, improper detailed scheduling and planning have been identified as the top factor contributing to the project delay [10]. Improper planning alongside the lacking experience, appropriate skills and knowledge, have been reported as significant reasons for recurring construction problems on substation projects, thus indicating human performance problems in a form of lacking or inadequacy of something [11]. One of the reasons stated inside [11] and related to "inherited problems from the earlier phase" might possibly be related to the engineering stage, as according to [12] design drawings should also describe the construction to be performed. However, while designing for the end state, designers might not take construction steps required to achieve such an end state into account due to lack of on-site experience and / or due to failing to perceive constructability [13]. While effective project management is stated to be the key for delivering "low cost substations" by focusing on cost optimization of a substation as a whole, designers play a vital role in the process of delivering cost-efficient substations in both developing and developed countries [9]. Integrating design and construction was proposed as a method for achieving such goals of effective project management [14]. As design of a substation involves a plethora of interrelated disciplines, necessary expertise, experience and skills must be available inside a project team [9]. Integrated design and construction, in essence, treats construction as one of the technical disciplines of a project team during the design phase in order to ensure constructability of those substation designs [14]. Integration of design and construction, historically viewed, was the responsibility of a "master builder" [15]. The term of the "master builder" is mostly perceived as a term relating to organizations knowledgeable and capable of providing both design and construction services [16], now only infrequently used to describe organizations utilizing the design/build project delivery method which embraces some of the concepts of the master builder approach [15], causing Contractors to identify themselves as master builders [17] For the energy and heavy industry sector, the master builder approach is reflected through Engineer-Procure-Construct (EPC) delivery method [18], and EPC method is sometimes being referred to as the turnkey method [9]

For substation projects, the turnkey method is most widely used [9]. As EPC is a highly competitive arena [19], Contractors are looking for different ways to differentiate themselves from the competition [20]. Being aware of competitive pressures, organizations are aligning themselves with market requirements, and are embracing $3 \mathrm{D}$ technologies for substation design [21]. In order to reduce project duration and installation costs as top reasons to innovate for Contractors possibly will even require changes to be made in the organizational structure, as according to [20]. Gaining competitive advantage through design-construction integration was proposed based on enabling a transfer of experience within a project team [14]. More effective integration of all project participants has been a goal of Virtual Master Builder (VMB) concept as a digital equivalent to the master builder figure from the antiquity [22]. Is there a way for Contractors to utilize VMB concept to deliver power substation projects effectively, and if so, what are requirements / recommendations to do so?

\section{LITERATURE REVIEW}

\section{CHASING THE ELUDING EXPERTISE}

The best substation design is seen as one that will most economically and safely supply adequate electric service for both present and future probable loads [23]. In order to design the best substation, the designer should have all the necessary relevant information and be knowledgeable of all potentially viable and applicable substation types [23]. Due to an incomplete set of information, the designer shall use his past experience resulting from similar problems in order to expand such an incomplete set of information, and this ability is usually directly related to the fact how many substations the designer has previously designed [23]. Generally, this number is said to be very small [23].

As reported inside [2], Contractors are aiming for international expansion where they may suffer from inexperience, lack of technical skills and expertise.

Related to the substation design, a lack of the experienced staff was reported to be a major risk factor due to a limited pool of expertise available worldwide [9]. According to [24], "today's engineers simply do not possess many of the proficiencies needed to compete internationally". In general, at the level of the industry, there is a lack of qualified managerial and engineering personnel [25]. Contractors do report trouble in filling salaried positions of both engineers and project managers, as hiring is reported to be more difficult when compared to a year ago [26]. These staffing challenges mostly result in higher prices in bids and contracts [26].

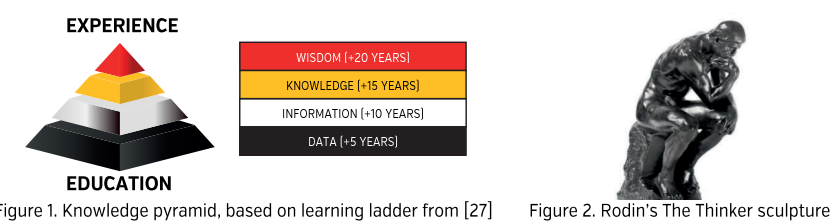

Figure 1. represents a view of the learning ladder depicted as a traditional Data-Information-Knowledge-Wisdom (DIKW) pyramid, leading from education to experience.

"Acceleration of experience" was being proposed to provide skills and knowledge through learning by conducting a work, but in a faster manner [27]. Similarly, "acceleration of learning" is also being proposed and based on time-compression applied on the learning process [28]. In both cases, final goal is to achieve expertise through experience in a faster manner.

Contractors are also mostly inclined towards initiating or increasing inhouse training, and towards providing of career-building programs leducation] [26]. While "training" aims to develop knowledge, skills and abilities to do the work, "education" aims to develop critical and basic skills [27]. According to [29], the workforce of tomorrow should have critical thinking skills, complex problem-solving skills, and judgement and decisionmaking skills.

\section{PERSONAL MASTERY}

\section{CRITICAL THINKING SKILL}

Critical thinking skill is defined as "using logic and reasoning to identify strengths and weaknesses of alternative solutions, conclusions, or approaches to problems" [30]. Deductive and inductive reasoning are two examples of reasoning [31], thus comprising critical thinking.

Term "Renaissance Engineer" is being used as a new vision for the engineer of the third millennium, and there is a tendency for engineering students to undertake some liberal education [32]. Historically viewed, engineering education as such was inseparable from learning liberal arts [33]. Logic, as the art of thinking, represents a natural desire for knowing "the reason why" in a search for the truth, and it is practiced through Trivium, as a part of the seven liberal arts [33]. Other four liberal arts are referred to as the Quadrivium [33].

It is acknowledged that organizations are starting to ask "why" things are done in comparisons to "how" things are done, as they need people capable of critical thinking [27], who should be educated to examine all aspects of the problem critically when facing it [34]. However, disciplinary courses in general rarely provide how, why and what, from a perspective of a larger meaning [35]. 
Figure 3. depicts three types of single-loop learning, each with its own center of learning.
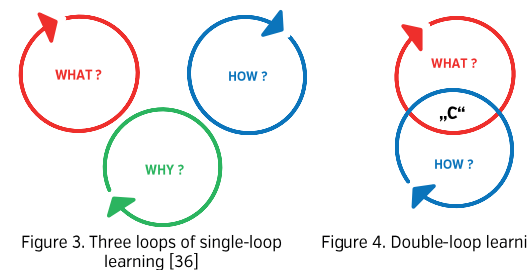

Figure 4. Double-loop learning [36] learning [36]

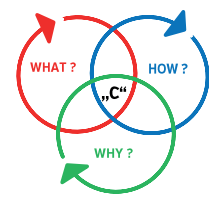

[36]
According to [36], learning inside each loop focuses on answering to a specific question, namely: what should we do, how should we do it, and why should we do it. Singe loop learning represents means-end thinking in which ends are set with a goal to discover the best means for meeting those ends, and these single-loop learners are task-oriented [36]. While single-loop learners perceive that identification of ends and the best means to achieve them is not problematic, for double-loop learners the definition of ends and means is problematic, as ends become accommodations or reconciliations among people [36]. Double-loop learning is depicted inside Figure 4. With double-loop learning a new consciousness is created between two centers of learning and is marked as " $\mathrm{C}$ ", thus causing de-emphasising of the task-oriented nature in favor of a wider perception of the task [36].

A new consciousness is also created with triple-loop learning for the purpose of being able to operate more intelligently and responsibly through increasing the fullness and deepness of learning [36], and is depicted inside Figure 5. In general, triple-loop learning is also concerned with a wider perception of the task, but with the purpose of creating a fair[er] practice, usually by resolving issues and managing dilemmas when facing them [36]. These issues and dilemmas may arise due to a collision in definition of ends and means as these are treated as non-problematic inside singleloop leaning and treated as problematic inside double-loop leaning.

There has been a reminder that engineering is a service profession which should take into account other factors beyond technical factors such as economic, social, environmental etc. when critically examining a problem [34]. An example of practicing a holistic view of design through different learning loops is given inside Figure 6.

While single-loop learning supports minor fixes or adjustments within governing variables, double-loop learning supports major fixes during which governing variables are usually changed [37]. It is triple-loop learning that goes beyond scientific insight and patterns towards the holistic view of economic, social, cultural and other factors, thus creating a shift in understanding the context or point of view for the purpose of understanding how problems and solutions are related [37].

In essence, multiple loops from Figure 6. converge into a design solution [37].

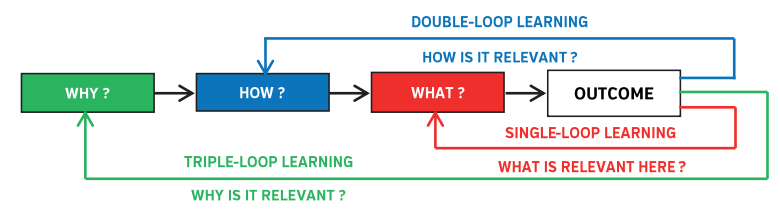

Figure 6. Usage of single-, double-, and triple-loop learning for converging into a design solution [37]

The requirement for double- and triple-loop learning resonates with the role of a design engineer, which according to [9], should study each situation to find an appropriate solution in order to spare resources, but also to learn about alternative available techniques that support realizing the optimum substation design solution. Such unique ideas / solutions leading towards substation optimization are encouraged to be brought forth during brainstorming sessions involving other disciplines as well [38], thus supporting the definition and examining many ideas for substation designs before narrowing it down to a single most cost-efficient one [39].

This is an example of applied critical thinking as both inductive and deductive thinking related to optimization of substation design and construction are practiced. Consciousness in double- and triple-loop learning from Figures 4. and 5. is related to interventionist's awareness of the centers of learning, thus gaining new information in order to examine prevailing yet unchallenged points of view by means of practicing conscious reflexivity [36].

In Jungian tradition of psychology, the conscious represents what we can know and experience, while the unconscious refers to all that remains beyond our cognitive reach or to that which is unknowable [40]. These two even though diametrically opposed are able to complement each other as the "individuation process" has a goal to integrate the unconscious into the conscious [40]. By "individuation process" we refer to learning process.

\section{COMPLEX PROBLEM-SOLVING SKILL}

While complex problem-solving skill is defined as "identifying complex problems and reviewing relevant information to develop and evaluate options and implement solutions" [30], conscious problem solving is defined as "an evolutionary process where actions are taken on basis of an evaluation of alternative scenarios, which is reflection" [41]. According to [27], engineers are experiential learners. Experiential learning can simply be described as "the process whereby knowledge is created through transformation of experience", through having a reflective observation on a previous concrete experience according to Kolb's Learning Cycle [42]. Scenarios are defined as temporarily ordered sequences of events, and the richness of alternative future scenarios depends on the richness of past experience [41].

According to [43], many design problems are so ill-defined and complex with uncertainties associated to both, the ends and means of a potential solution. The entire construction process is riddled with uncertainties thus making it an ill-defined problem in its entirety [44]. Available technical tools [the existing professional body of knowledge] are seen as insufficient to manage complicated and complex projects [45], and the project manager alone cannot be a sole hero of a project anymore [46]. "Artificial tools and methods" alongside "Cannot try before build" are stated to be some of the reasons making construction a risky business [47]. Figure 2. depicts our view of a modern professional when facing ill-defined problems that require solving.

Designers, engineers and managers are reflective practitioners who deal with "messy" situations by means of conducting a conversation with the unique situation at hand trying to make sense of the problematic situation [48]. As the situation is complex and uncertain, there is a problem to find the problem [48]. Constructing and understanding the situation is the first thing to do in order to find the problem by reframing the problematic situation into one dealt with before, as a new problem is seen as a variation of an older problem [48]. It is these built-up repertoires of examples / understandings / actions that are built by previous experiences through practicing reflection-in-action [48]. Reflection-in-action necessarily involves experimentation as an activity to see where the action leads to, but fundamentally answers the question "what if" [48]. In essence, such an exploratory experiment involves experimentation, move-testing and hypothesis testing [48]. Problem solving, as such, is only a part of a larger experiment in problem setting [48]. Reflection-in-action for managers is fundamentally similar to reflection-in-action practiced by designers and engineers for resolving "messes" [48], as sets of interacting problems within complex systems [41].

\section{JUDGEMENT AND DECISION-MAKING SKILL}

Judgement and decision-making skill is defined as "considering the relative costs and benefits of potential actions to choose the most appropriate one" [30].

Governing variables are defined as preferred states that interventionist strive to "satisfice" when they are acting [49]. These governing variables do not represent deeper underlying beliefs of an interventionist, but do represent variables that can be inferred [49]. Governing variables as deeper beliefs are accustomed to triple-loop learning.

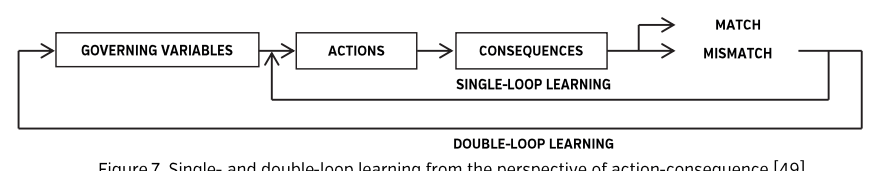

When a match or a mismatch exists between the preferred state [governing variables] and the consequence of actions exist that is corrected by changing actions, it is said that single-loop learning has occurred in that case [49]. Double-loop learning occurs when mismatches are corrected by examining and altering the governing variables [preferred state] first and then through action [49]. Double-loop learning will be required for a practitioner to solve a complex problematic situation, instead of singleloop learning [50].

According to [51], decision-making process in its simplest form can be de- 
scribed as "finding the best solution among the set of alternatives having sound preferences that trigger the right course of action".

For the power substation design, as according to [51], using existing repertoires of action based on the standardization is closely related to the practice of standardized equipment, standardized designs and standard substation layouts, thus relating to agile companies, and namely agile Utilities. This is depicted by the blue line inside Figure 8 , which allows deciding stage of the decision-making process to be skipped [51]. It is also argued inside [51] that all other companies differing from agile Utilities cannot skip the decision stage inside the decision-making model, in order to identify the best solution as the most cost-efficient one. Figure 8 is based on Boyd's Observe-Orient-Decide-Act [OODA] loop as a single-agent model for dynamic decision-making, and the Orient stage is of the paramount importance to an entire decision-making model as it "guides" observation of information and "drives" decisions and actions [51]. Lean Project Delivery System (LPDS) is placed at the center of Orient stage, making it a core of a decision-making model when pursuing optimization / cost efficiency [51].

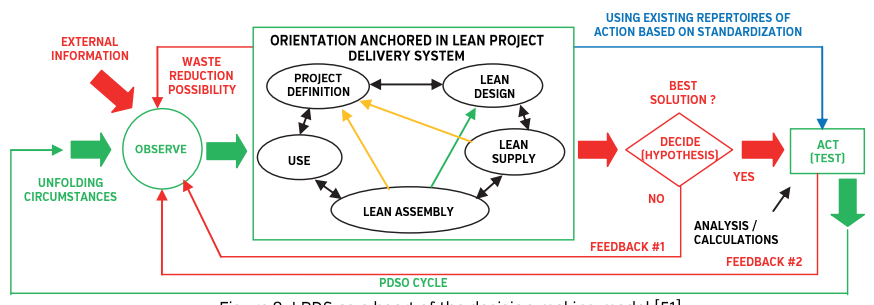

For the purpose of this paper, a green arrow between Lean Assembly and Lean Design represents application of constructability. In order to arrive to the best solution (with an exception of utilization of the blue line), cycling through feedback loops is inevitable [51].

\section{CORE LEARNING CAPABILITIES FOR TEAMS}

While deductive reasoning is largely covered by available scientific tools, available scientific tools still do not cover the majority of inductive reasoning. For that purpose, we assume that individual skills covered inside chapter 2.2. are taken as skills relevant for personal mastery, as according to [52], personal mastery is about seeing the reality objectively.

Figure 9. depicts core learning capabilities for teams and personal mastery is one of them.

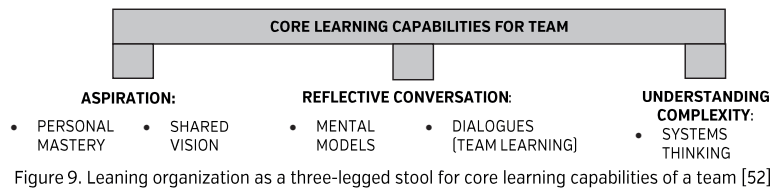

Personal mastery is a base for developing of a shared vision which usually represents shared "pictures of the future" that foster commitment [52]. According to [53], people today are no longer satisfied with "just having a job", but are multi-functional, flexible, talented and most importantly, goaloriented. A move towards self-directed and self-sufficient teams consisting of multi-skilled individuals was proposed to large hierarchical systems as an opposition to demanding compliance [53]. "Creeping managerialism" is a problem of today's project management [47]. While the empowering staff has been reported to be the most powerful force behind the substation cost reduction [39], on the other hand commitment was identified as an enabler of a drastic compression in the schedule [38]. Another core learning capability for a team is team learning [52]. Team learning is about developing skills of groups of people to see a larger picture laying beyond their individual perspectives, and it starts with "dialogue" as a capacity of the team to suspend assumptions and get down into genuine thinking together as a team [52]. According to [52], team learning is vital, because teams, and not individuals, represent a fundamental learning unit in organizations. The ability to look at the "big picture" while communicating issues and solutions is identified to be a major contributor to the project success [13]. Project team roles and responsibilities should be clearly defined [9] as TEAM meaning "Together Everyone Achieves More" [53] Mental models are about perceiving the world and are changed by removing walls between disciplines [52]. Design-construction integration is just one example.

\section{INTEGRATION OF DESIGN AND CONSTRUCTION}

According to [54], the project engineer is responsible for engineering and design as depicted inside Figure 10. However, from the same figure it can also be seen that the project engineer is a figure standing in between project manager and design / engineering roles. According to [55], "Project Engineering is nothing but the integration of all the different aspects of an EPC project", and is depicted inside Figure 11.
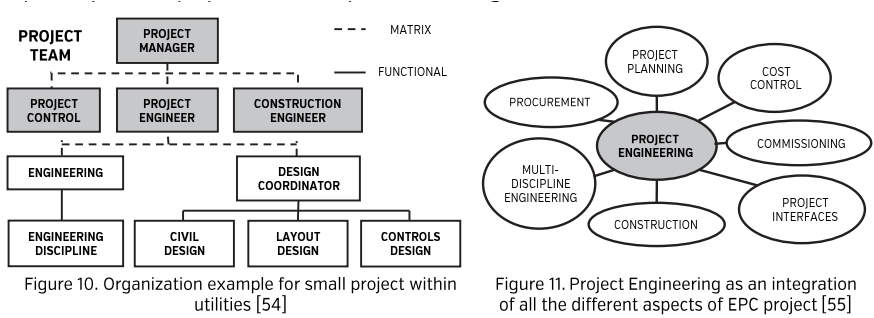

Figure 11. Project Engineering as an integration
of all the different aspects of EPC project [55]

Integration of design and construction should involve both, horizontal and vertical integration [14]. While horizontal integration involves integration of different disciplines within the same project phase with the purpose to achieve coordination, vertical integration involves integration of project phases, as according to [14], and depicted in Figure 12. If construction management / engineering is treated as one of disciplines involved in horizontal integration with other technical disciplines, and under vertica integration of design and construction phases, a ground for the most effective application of constructability is created [14].
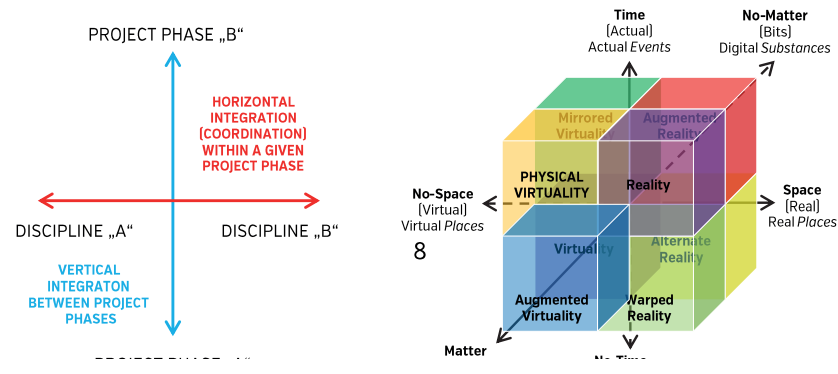

Figure 12. Vertical and horizontal integration of

Figure 13. Multiverse concept comprised of eight realms design and construction [14]

Constructability requires a balance between design and construction needs, and is interdisciplinary in its nature [56]. As a result, differences between project phases become blurred requiring functional project teams that have a complete project perspective [57]. Constructability as such plays a more prominent role in the new process [58]. New processes should also focus on improving communication among project team members as well [59].

Higher integration of project processes is advised in order to fight one of the problems of contemporary project management, namely "discontinuity in construction processes" [47].

\section{OVERCOMING "LEARNING HORIZON" AND THE MULTIVERSE}

While personal mastery is seen as an essential cornerstone of organizational learning and its spiritual foundation, system thinking is seen as its capstone that integrates other four core learning capabilities and provides for insights to understand complexity [52]. Within complex systems, decisions and consequences of actions are distant in space and time, preventing in such a way gradual development of learning and maintaining a direct experience as a result of the "learning horizon" [52]

While Senge spoke about "microworlds" as the technology for the Learning Organization [52], Schön spoke of "virtual worlds" for professional practice and development through practice of reflection-in-action [48]. Underlying similarity of both of these "worlds" is the ability to allow "compression of time and space", isolation of variables for experimentation purposes involving cause-effect simulations, move-probing and hypothesis-testing, all conducted inside such a "world" as a risk-free environment, enabling removal of pressures associated with real decision-making in regards to suffering the consequences of selected actions. That are exactly those "worlds" as environments that can provide a unique insight into the future 
overcoming limitations imposed by the "learning horizon", and enabling in such a way a development of learning from direct experiences [52].

Organizational learning is regarded as a competence all organizations should develop [49]. Organizations themselves do not learn but are able to create conditions for individuals to learn effectively [49]. Created conditions should support development of double-loop learning [49].

According to the progression of the economic value, services can stage experiences and experiences can quide transformations [60]. When three new axes of "no-space", "no-time" and "no-matter" are added above axes of "space", "time" and "matter", the concept of a Multiverse is created comprising eight realms all of which are capable to stage experiences [60], and those experiences are formed through five human senses [41].

The concept of Multiverse is depicted in Figure 13. The focus of this paper is placed in the realm of Physical Virtuality. "Instantiating the virtual in the material, Physical Virtuality takes an experience happening in a virtual place and then instantiates, or realizes, it in the real world; first you dream it, then you build it", and it is the domain of the Computer Aided Design [CAD] software [6o].

\section{PHYSICAL VIRTUALITY FOR SUBSTATION DESIGN AND CONSTRUCTION}

It was believed that Virtualization Technology [VT] can reduce the cost of design, construction and maintenance of major facilities such as substations [61]. 3D modelling was seen as a door opening up new avenues for efficient substation construction [62]. Incorporation of three-dimensional modelling techniques into substation design simplifies the design process and allows non-technical professionals to have a better understanding of the design concept [63]. Fly-through and walk-thoughts are helpful for receiving opinions including accessibility and constructability, with a final goal to reduce potential design errors due to unforeseen construction expenses and delays [63]. The construction crew can be thus involved during the design process giving suggestions and helping to identify problems [39], as the coordinated system of construction minimizes the time and the cost required for detailed engineering and field assembly [64]. 3D modelbased approach provides means for gaining and exploring "the big picture" for construction crews [58]. As a reduced schedule with a minimized cost has become the predominant theme in most electrical infrastructure projects [63], Contractors should identify all potential delay factors in both, the design and the construction phase [10]. The Contractor can avoid expensive construction problems simulating the construction of the facility and developing a construction plan [61]. 3D models have been seen as an enabler of more optimized construction sequencing [65]. Combining 3D CAD models with construction sequencing facilitates the development of effective substation construction plans through schedule optimization [66].

Design tools enable users to experience differences between options and possibilities through visualization [6o]. However, 3D visual design tools are not enough in many situations and should include the fourth dimension of time added onto a virtual 3D model to make experience memorable and transformational when compared to the experience associated to $3 \mathrm{D}$ models only [6o]. Those models with the time dimension associated to three spatial dimensions are being referred to as $4 \mathrm{D}$ models [6o].

4D models represent a graphic simulation of the construction process in a determined time unit [67], as $4 \mathrm{D}$ model is made from a combination of a 3D model with an activity / task from a Gantt chart [68].

The process of substation construction and installation is suggested as a topic to be included in the training materials [69]. As advised according to [11], recurring construction problems on substations can be resolved using conventional managerial approaches including training and carefu planning. Training materials should focus on the topics of how to plan the job, how to develop a realistic schedule, how to develop a detailed estimate and budget, how to track the progress and spot potential problems [70]. Such training materials dealing with real-life requirements for tasks involving design and construction substation projects are mostly not available as "off-the-shelf" products and should be developed internally by the company [70], while being visually enhanced as much as possible [69].

VT has been believed to be an enabler of a greater reduction of costs for training while increasing the productivity of training Transmission and Distribution (T\&D) personnel [61]. Building Information Modelling (BIM) tools have allowed engineers to improve their response capacity and provide the faster learning curve for new substation designers [67].

"Accelerated learning" and accelerated training have been reported as advantages of 3D substation design software as these can capture some of the experience of the retired workforce [71]. 3D substation design tools have been seen as a design process improvement [72].

\section{BIM AND VIRTUAL DESIGN AND CONSTRUCTION}

3D models are seen as facilitators of interdisciplinary coordination [65], which is stated to be one of the prime benefits of BIM [67]. BIM is also seen as an enabler of a greater collaboration among the design and construction disciplines, but also as a platform for collaboration throughout the project design and construction [25]. In general, BIM has been seen as a "transformational trend" [25], as proven advantageous to project teams [65]. From the context of substation design, BIM is defined as a tool used "to determine critical cost factors in the early substation planning phase, shift the time, effort and cost structures to earlier phases in the substation planning - enabling better decision making" [73]. Decision-making models should be transformed leaving behind models of "linear thinking" in favour of embracing shared understanding of interrelationships. In general, decisions are made based on available information / knowledge, thus meaning that management of a construction project is about managing the project information flow [47]. Just "ineffective information / knowledge management" is one of the reported problems of the contemporary project management rooted inside a lack of a uniform platform where information / knowledge can be stored and retrieved as wished [47].

According to [74], Virtual Design and Construction (VDC) has been ultimately trying to bridge the expertise gaps between design, construction and operations and is defined as "an interdisciplinary practice in which data is centralized, typically within a $3 D$ information model, allowing for increased efficiencies and deeper project understanding and analysis". VDC processes seek to apply new technologies and to link the work conducted by the members of the project team into the information model, the one that acts as a hub [74].

For VDC practice, BIM is viewed only as an "information model" and two core information models are relevant, namely design intent models and construction models [74]. While design intent models are created for the purpose to visualize and understand the integration of all different systems in 3D space, construction models are created with a greater level of detail to represent what is actually installed [74]. Construction model can also represent the existing conditions for brownfield projects [74]

Generic overview of a VDC practice diagram is given inside Figure 14.

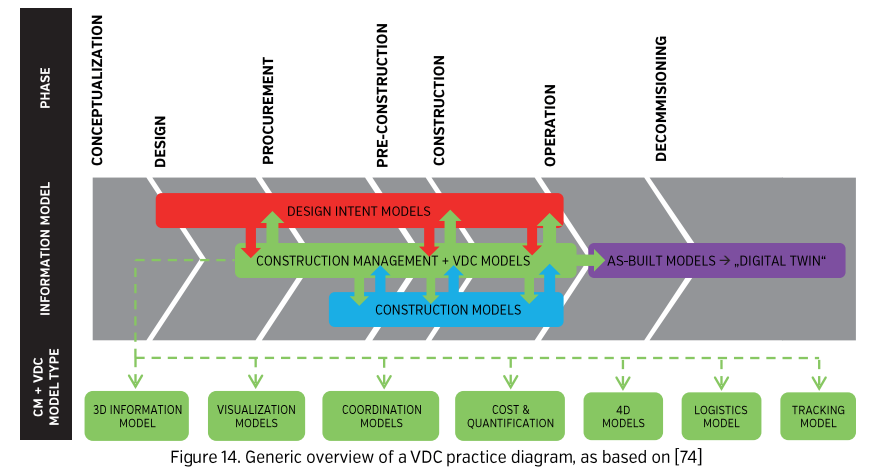

Construction management (CM) and VDC models as a mixture of both design intent models and construction models ensure that intended designs are built in the best possible way, at the lowest cost and in the most time-efficient manner [74]. These models include 3D information model, visualization models / experience simulation models (walkthroughs and flythrough), coordination models as a composite model (primarily used for clash detection between systems and for constructability reviews), cost and quantification models (in which quantity information is connected to quantity calculations and then linked to a cost estimation database), 4D models (for visualizing schedule and understanding construction sequencing), logistics models, and tracking models (comparing actual site work progress with planned progress) [74].

The concept of as-built models for operation is similar to a "digital twin" concept.

VDC model types are used as a base for realization of VDC services [74]. According to [74], and depending on a VDC model, these services are typically related to:

- For 3D information model, VDC services may include: model quality control, constructability studies, virtual mockups, field capturing, etc.; 
- For visualization model, VDC services may include: experience simulation, contract scope visualization, 3D printing, systems visualization, etc.;

- For coordination models, VDC services may include: design coordination, CM coordination, construction coordination, clash detection, etc.;

- For cost \& quantification models, VDC services may include: cost estimating, quantity take-offs, etc.;

- For 4D models, VDC services may include: sequence simulation, 4D scheduling, etc.;

- For logistics model, typical VDC service is related to logistics and site safety modelling;

- For tracking model, typical VDC service is related to progress planning and tracking.

VDC is seen as an enabler of the design and construction integration.

\section{PURSUING EFFICIENCY AND DIFFERENTIATION THROUGH VDC}

Organizations aim either at "red ocean" or "blue ocean" competing strategies [75]. While "red ocean" strategies focus on either seeking efficiency through lower cost or seeking differentiation through introduction of marginal innovations, "blue ocean" strategies aim at seeking value innovation by introducing radical innovations [75]. Figure 15. depicts Value leve as vertical axis, while five interaction types are represented on horizonta axis, with a demarcation line between "blue ocean" and "red ocean", al based on [75].

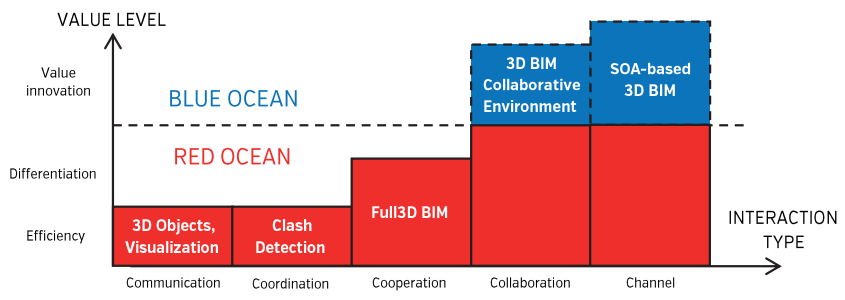

Figure 15. Value level of interoperability for BIM [76], as based on [75]

According to [76], differentiation is achieved through Full3D BIM and Coop eration by focusing on obtaining of time and cost savings through applying construction sequencing and visualizing constructability based on 3D models. Also, costings done directly from a model is defined as an enable for differentiation [74]. That means that VDC services utilizing VDC models such as cost and quantification and 4D models are classified as enablers for achieving level of differentiation, as per Figure 15. The value of efficiency as according to [76] and seen on Figure 15. is related to utilization of 3D objects, visualizations and clash detection, meaning that value of efficiency is related to usage of VDC models and namely: 3D information models, visualization models and coordination models. Having appropriate information systems set in place is a primary prerequisite for all interaction types [75] here namely for Communication, Coordination and Cooperation. Impact on business processes is expected for interaction types of Coordination and Cooperation, and impact on organizational culture and employees is expected as an impact for interaction type of Cooperation [75]

This means that in order to achieve value level of differentiation through Cooperation by a progress from efficiency [through Communication and Coordination], information systems, business processes, and organizational and employee culture are all impacted [75].

\section{VIRTUAL MASTER BUILDER CONCEPT AND CONTRACTOR'S TO-DO LIST}

According to [22], Virtual Master Builder (VMB] concept has been proposed for the following purposes: [1] enabling fully integrated construction process; [2] being an interactive environment for generating plans and designs, critique and evaluate proposals and for conflict resolution; [3] integrating all project stakeholders and participants; (4) supporting integrated framework spanning an entire project cycle; [5] displaying facility model in 3D for gaining a global view on the entire facility; [6] enabling Concurrent Engineering [CE]; [7] providing feedback mechanisms and opportunities for innovation and optimization; and [8] providing mechanisms where collective skills of the participants are aimed at a common goal.

The primary objective of VMB is to "substitute computer-based communication, coordination, and cooperation for organizational control" [22]. Here we draw a parallel between communication, coordination, and cooperation with these as interaction types from chapter 2.8., but we also draw a parallel between VMB and VDC / BIM, and the following is argued:

- VMB concept is reflected inside a VDC concept;

- Differentiation level is achievable through utilization of 4D VDC models and will have an impact on business processes and organizational and employee culture;

- Business processes should be changed to support integration wherever possible;

- Employees should focus on personal mastery and on developing individual skills;

- Organizations should use collective mechanisms to develop agile project teams;

- Organizational learning is a key competence for delivering substation projects, and;

- VDC is an enabler of "accelerated learning" and of meaningful experiences to all.

Following current trends, the company has embarked on a "differentiation journey" with VDC.

\section{PROJECT CASE FOR SS 380/110 kV SKOPJE 4 REHABILITATION}

Skopje 4 SS 380/110 kV was first 380 kV substation to be built on the territory of Republic of North Macedonia during the 1970's, as a part of former Yugoslavian "Nikola Tesla" $380 \mathrm{kV}$ ring. The rehabilitation scope included replacement of almost all $110 \mathrm{kV}$ primary equipment, replacement of the majority of $400 \mathrm{kV}$ primary equipment, the relay house rehabilitation, rehabilitation of cable trenches and their covers [where necessary], replacement of secondary equipment and of AC/DC systems, with a requirement for installing of a completely new cabling. Due to the difference in today's standards and regulations compared to ones from the 1970's, and in order to arrive to the best solution that satisfies all the relevant requirements, a double-loop learning was a necessity due to a requirement for examination of governing variables. These governing variables were related to voltage and safety clearances, sag and wire tension definition, environmenta conditions, load combination on the conductors, influence of spacers on the value of forces due to a three-pole short-circuit, etc. Seeking answers relating to what, how and why was a necessity. In order to do so, both 3D substation design intent models and a 3D construction model (depicting existing situation] were created inside "primtech". Examination of governing variables was conducted inside "primtech" utilizing integrated calculations, interference checks and clash detection. Furthermore, VDC models as a 3D coordination model and $4 \mathrm{D}$ model were created for the purpose of conducting constructability reviews and optimizing construction sequencing. Figure 16. depicts a 4D model used for two $110 \mathrm{kV}$ OHL bays with installation process depicted as a green color. Knowledgeable construction personnel were brought up-front with the design team and were treated as a separate technical discipline inside our project team, thus enabling our design team to focus on standardizing designs and materials, supporting ease of installation. As a result, an updated construction methodology document was created and construction activities were defined more accurately. The usage of resources was also defined more accurately, leading to the construction schedule optimization. "Information model" became the project team's hub.

That has led to connection of patterns not previously linked, as a definition

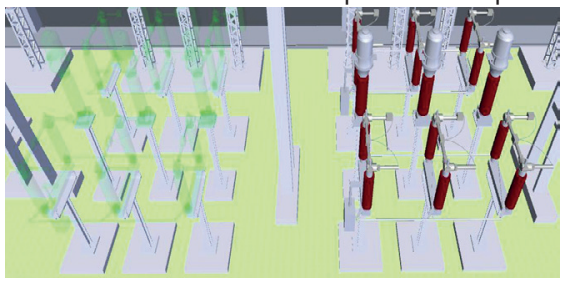

Figure 16. Rehabilitation of each relay house and construction sequencing applied on two $110 \mathrm{kV}$ bays (left and right of relay house)

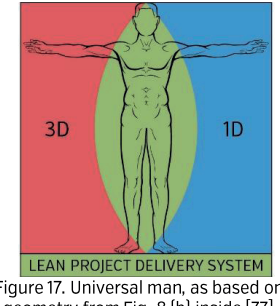

of creativity [41]

Creativity is stated as one of the skills required for the future workforce [29]. Let us create... 


\section{ADVANCING DESIGN AND MANAGEMENT (ADAM)}

The engineer required by the industry of today resembles the "renaissance man". A $21^{\text {st }}$ century engineer should to be trained for interdisciplinarity. $\mathrm{He}$ would need to think in a systems manner [41], and have a breadth of vision [32]. While the "master builder" is about being in charge and in control of all aspects of the project [17], Project Engineering is about integration of these aspects of EPC project [71]. Here, we see Project Engineering as a middle ground between design and construction stage, but also between engineering and management roles. Engineering, like the rest of professions, is a mix of both "art" and "science" [9]. According to [9], "the "art" of knowing what works best in each situation, which is gained through experience, will guide the "science" to achieve its best results". This definition of "art" resembles to definition of art, according to [48], as a skill for action relating to "knowing (reflection)-in-action". Knowledge as such is a set of mental models [41], which guides the decision-making process [69]. In order to achieve cost-efficient substation solutions, mental models should be aligned with LPDS. For that purpose, we see a man standing on the LPDS body of knowledge on Figure 17. Under definition of "science" we understand the usage of specialized scientific tools. His left hand is immersed into project and construction management professions, while his right hand is immersed into multidiscipline engineering professions, thus utilizing agile decision-support tools to perform tasks inside a dynamic and complex environment. In doing so, he strives to achieve the "unity of opposites" inside of a "space-time" environment, obtaining the "mastery" in his practice through learning-by-doing involving experimentation as double- / triple-loop learning, thus leading to a personal transformation from unnatural and troubled state depicted inside Figure 2. to a natural and self-confident state depicted inside Figure 17. as a representation of the Universal man striving for self-realization following the middle path, one that we identify here as Project Engineering. Figure 17. is based on notes by Vitruvius, Roman master builder.

\section{CONCLUSIONS}

Virtual Master Builder (VMB) as a concept for organizational integration through communication, coordination and cooperation [22], is available for project teams through Virtual Design and Construction (VDC) [74]. VDC is seen as a solution supporting effective project management [47], through which problems on substation projects reported inside [11] can be addressed. VDC is seen as an enabler of meaningful experiences that guide transformations towards delivery of substation projects on time, within a budget and of a required performance, supporting recommendations given inside many of CIGRE SC B3 TBs, and especially those given inside TB 740. It is up to Contractors to provide environments, change processes and deal with "organizational defences" to support VDC application on power substation projects, enabling delivery of cost-effective substations by pursuing differentiation. Individual competencies should be translated into collective ones [46].

\section{RECOMMENDATIONS}

Future papers on this topic could relate to introduction and utilization of five-dimensional (5D) BIM models (4D + cost) for power substation design and construction. Utilization of 5D BIM models could be put in the context of Value Engineering. Definition of VDC practice diagram and process for power substation projects is also a promising avenue to be explored.

\section{ACKNOWLEDGEMENTS}

During 2019 while envisioning the title and the scope of this paper, the authors were inspired by the $40^{\text {th }}$ anniversary of an achievement made in 1979 when the top of Mt. Everest was ascended by opening a new "West Ridge Direct" route, which according to [78], may represent the most difficult route to the top. It is this idea of walking on the edge to balance between emphasised government and efficiency and creativity and responsiveness in organizational systems, which could, according to [79], generate new forms of work and methods of achievement. A fine example of this is a sheer personal willpower coupled with 3D modelling, construction sequencing and various analysis tools, which according to [80], have allowed testing of internal ramp hypothesis on how the Great Pyramid was built. Here we see even triple-loop learning being applied. This paper is dedicated to all individuals, project teams and organizations walking the middle path as a path less travelled.

To knowing oneselves.

\section{BIBLIOGRAPHY}

[1] J. Jonnes. Empires of Light: Edison, Tesla, Westinghouse, and the Race to Electrify the World 2003, Random House Trade Paperbacks.

[2] KPMG International. "Global Construction Survey 2013 Ready for the Next Big Wave?", Report, October 2013

[3] M. Hinow, M. Waldron, L. Müller, H. Aeschbach \& K. Pohlik. "Substation Life Cycle Cost Management Supported by Stochastic Optimization Algorithm" (Proceedings of the CIGRE Session 2008, August 2008, Paper B3103 , pages 1-9].

[4] G. Balzer \& C. Neumann. "Asset Simulation and Life Cycle Assessment for Gas Insulated Substation" (Proceedings of the CIGRE 2011 Recife Symposium, April 2011, Paper 87, pages 1-10].

[5] Working Group B3.15 CIGRE. "Guidelines to Cost Reduction of Air Insulated Substations" Technical brochure 354, Augus 2008.

[6] Working Group B3.38 CIGRE. "Management of Risk in Substations", Technical brochure 734 June 2018

[7] Y. Nonaka, T. Nakano, K. Ohya, A. Enomoto, G. Erdős, G. Horváth \& J. Váncza. Engineering Support Systems for Industrial Machines and Plants, in: L. Redding et al, eds. Advances in Through-life Engineering Services, Springer, Engineering Services, Springer,
chapter 13, pages 199-220, 2017.

8] P. P. Kumar. "Effective Use of Gantt Charts for Managing
Large Scale Projects" [Cost Engineering, Vol. 47, No. 7, July 2005, pages 14-21].

[9] Working Group B3.43 CIGRE. "Contemporary Design of Low Cost Substations in Developing Countries", Tech

[10] N.-J. Yau \& J.-B. Yan. "Factors causing design schedule delays in turnkey projects in Taiwan: An Empirical Study of Power Distribution Substation Projects (Project Management Journa, Vol.43, No. 3, June 2012, pages $50-61$.

[11] C. S. Lim \& M. Zain Mohamed. "An exploratory study into recurring construction problems" (International Journal of Project Management, Vol. 18, No. 4, August 2000, pages 267-273).

[12] J. R. Lusby. "Fundamental Concepts in Substation Design $\left(37^{\text {th }}\right.$ Annual Rural Electric Power Conference 1993, April 1993, Paper 93 D2, pages 1-25)

[13] M. E. Roos \& K. Kallis. Building "Constructability" into the Design, in: A. D. Pugh, ed. Proceeding of the Electrical Transmission and Substation Structures Conference 2012: Solutions to Building the Grid of Tomorrow, ASCE, pages 323 335, November 2012.

[14] C. B. Tatum. "Integrating design and construction to improve project performance: a proven key to organizational teamwork and a breakthrough in plannin performance" (Project Manage- ment Journal, Vol. 21, No. 2, June 1990, pages 35-42).

[15] E. L. Flavell. "Master Builder: Historical Icon?" (Leadership and Management in Engineering, Vol. 11, No. 2, 2011, pages 78-79).

[16] J. K. Yates \& L. C. Battersby. "Master Builder Project Deliven System and Designer Construction Knowledge" (Journal of Construction Engineering and Management, Vol. 129, No. 6 , 2003, pages 635-644).

[17] M. D. Kirschenman. "Leadership of Multidisciplinary Programs and Systems" (Leadership and Management in Engineering, Vol. 11, No. 2, 2011 pages 137-140).

[18] G. Carlson. "Integrated Project Delivery: Bringing Back the
Master Builder" (Amplified Perspectives, November $8^{\text {th }}, 2017$, spectives, November
Burns \& McDonnell).

[19] K. R. Nielsen. Governance of the Megaproject, in: P. D. Galloway et al, eds. Managing Gigaprojects: Advice from Those Who've Been There, Done That, ASCE, pages 5-30, 2013.

[20] Working Group B3.11 CIGRE. "Combining Innovation with Standardization", Technical brochure 389, August 2009.

[21] A. D. Dragan, A. Dina, M Popovici \& I. E. Chitescu. HighVoltage Electrical Substation Design Using 3D Software ( ${ }^{\text {rd }}$ Proceedings of CIGRE Romanian Conference on Condition Monitoring Diagnosis, and
Maintenance: Modern Mangement Technology (CMDM 2015), October 2015, Paper 110 , pages $80-86$ )

[22] V. E. Sanvido, S. J. Fenves \& J. L. Wilson. "Aspects of Virtua Master Builder" (Journal of Professiona essional Issues in Engineering 118. 118, No. 3, July 1992, pages

[23] Y. B. Mahdy, E. K. Stanek, M. Abdel-Salam \& M. Zaki. "An Expert System for Specifying the Major Substation Components: Machine Learning Appron Confer Conference Record of the 199 EEE Industry Applications So1991, pages 1216-1222).

[24] P. D. Galloway. "Educating the Master Builder of the $21^{\text {st }}$ Century Strategically" (Leadership and Management in Engineering Vol. 11, No. 2, 2011, pages 103-112).

[25] J. Hinchey. Dispute Resolution in: P. D. Galloway et al, eds. Managing Gigaprojects: Advice from Those Who've Been There, Done That, ASCE, pages 229 262, 2013.

[26] Associated General Contractors of America \& Autodesk. "2019 Workforce Survey Results: National Results", Report, 2019.

[27] C. C. Trudel-Ferrari. "Accelerating Experience - Utility Sector Case Studies in Training and Knowledge Management" (Proceedings of CIGRE Canada Conference on Power Systems 2010, October 2010, Paper 153, 
pages 1-11)

[28] R. R. Hoffman, P. J. Feltovich, S. M. Fiore, G. Klein \& D. Ziebell. "Accelerated Learning (?)" (IEEE
Intelligent Systems, Vol. 24, No. 2, 2009, pages 18-22).

[29] World Economic Forum. "The Future of Jobs: Employment, Skills and Workforce Strategy for the Fourth Industrial Revolution?", Global Challenge Insight Report, January 2016.

[30] Z. Shen \& W. Jensen. "Civil Engineers as Master Builders and the Professionalization of Construction" (Leadership and Management in Engineering, Vol. 11, No. 2, 2011, pages 169-181].

[31] Y. B. Mahdy, E. K. Stanek, M. Abdel-Salam \& M. Zaki. "Learning Design Rules and Concepts from Examples - A Case Study to Design an Electric Power Substation" (Conference Record of the 1991 IEEE Industry Applications Society Annual Meeting. Vol. 2, 1991, pages 1206-1215].

[32] M. E. Jones. "The Renaissance engineer: A reality for $21^{\text {st }}$ Century" (European Journal of Engineering Education, Vol. 28, No.
2, June 2003, pages 169-178].

[33] Sister Miriam Joseph. The Trivium in College Composition and Reading, $3^{\text {rd }}$ edition revised, 2014, Martino Publishing.

[34] D. J. Moore \& D. R. Voltmer. "Curriculum for an Engineering Renaissance" (IEEE Transactions on Education, Vol. 46, No 4 November 2003 . paes 452-455).

[35] J. L. Herman, L. Hall, D. Kuzawa, L. Wahlin \& M. Faure. Writing as Knowing: Creating Knowing through Multiple Messaging Modes in an Engineering Technical Communications Course, in: D. Bairaktarova \& M. Eodice, eds. Creative Ways of Knowing in Engineering, Springer, pages 99-120, 2017.

[36] R. L. Flood \& N. R. A. Romm. Diversity Management: Triple Loop Learning, 1996, John Wiley \& Sons

[37] S. Iwata. Towards Data Democracy beyond Fukushima, in: T. Taura, ed. Principia Designae - Pre-Design, Design, and Post Design: Social Motive for the Highly Advanced Technological Society, Springer, pages 105120, 2015.

[38] K. T. Clebak Jr., B. A. Nelson, B. Shvartsberg \& J. Solinski. "Federal square $138 / 4 \mathrm{kV}$ substation as an example of modern distri- bution substation constructed on a design/build basis" (Proceedings of the $33^{\text {rd }}$ Annual PM Seminars, October 2001].

[39] Arizona Public Service. "APS team works smarter, cuts substation construction costs by 36\%" (Electrical World Magazine, May 1993, pages 52-54].

[40] L. Huskinson. Nietzsche and Jung: The Whole Self in the Union of Opposites, 2004 Bruner-Routledge.

[41] D. I. Blockley. "Engineering from Reflective Practice" [Research in Engineering Design, Vol. 4, No. 1 1992, pages 13-22].

[42] D. A. Kolb. Experiential Learning: Experience as the Source of Learning and Development $2^{\text {nd }}$ edition, 2015, Pearson Education.

[43] M. Whelton \& G. Ballard. "Wick ed Problems in Project Definitions" (Proceedings of $10^{\text {th }} \mathrm{An}$ nual Conference of the International Group for Lean Construction [IGLC 2002], August 2002, tion [IGLC 2002)

[44] F. Castronovo, S. E. Zappe, J. I. Messner \& R. M. Leicht. "Design of a Construction Simulation of a Construction Simulation Educational Game through a Cognitive Lens" (Proceedings of Exposition, 2015, pages 1-15].

[45] L. Crawford, P. Morris, J. Thomas \& M. Winter. "Practitioner development: From trained technicians to reflective practitioners Management, Vol. 24, 2006, pages 722-733].

[46] S. Loufrani-Fedida \& S. Missonier. "The project manager cannot be a hero anymore! Understanding critical competencies in project-based organizations from a multilevel approach" (International Journal of Project Management, Vol. 33, 2015 pages 1220-1235].

[47] H. Li, W. Lu \& T. Huang. "Rethinking project management and exploring virtual design and construction as a potentia solution" (Construction Management and Economics, Vo 27. No. 4. April 2009, pages 363-371].

[48]D. A. Schön. The Reflective Practitioner: How Professionals Think in Action, 2016, Routledge.

[49] C. Argyris. On Organizational Learning, $2^{\text {nd }}$ edition, 1999 Blackwell Publishing.
[50] C. Argyris \& D. A. Schön. Theory in Practice: Increasing Professional Effectiveness, 1992, Jossey-Bass.

[51] A. Foškulo \& M. Kokoruš "Streamlining the DecisionMaking Process on Tubula Rigid Busbar Selection During the Planning / Designing Stage by Utilizing $3 \mathrm{D}$ Substation BIM Design Software" (Proceeding of the CIGRE Session 2018, August 2018, Paper B3-210, pages 1-17].

[52] P. M. Senge. The Fifth Discipline: The Art \& Practice of The Learning Organization, $2^{\text {nd }}$ edition, 2006, Random House Business Books.

[53] R. D. Phillips Jr. "Teams - a solution to utility competition" lution to utily competition" PMI Seminar / Symposium 1996, October 1996].

[54] V. Scatuccio Jr. "Managing Small Projects within a Utility" [1992 AACE International Transactions, June / July 1992, paper 0.3 pages 1-9].

[55] S. Moulik. Project Engineering \& Management Textbook, February 2012, AuthorHouse

[56] C. B. Tatum. "The Project Manager's role in integrating design and construction: A process view" [Project Management Journal, Vol. 18, No. 2, June 1987 pages 96-107].

[57] D. R. Riley \& V. E. Sanvido. Educating Future Master Builders, in: J. P. Mohsen, ed. Computing in Civil Engineering: Proceedings of the $2^{\text {nd }}$ Congress held in conjunction with A/E/C Systems, Volume 1, ASCE, pages 449-452, Volum 1995.

[58] A. Fry. "Duke Energy Transforms Its Substation Design Process" [Electric Energy T\&D Magazine, November / December 2009, pages 24-27).

[59] F. Hartman \& R. Ashrafi. “Project management in the utility and infrastructure industries" (Proceedings of the $28^{\text {th }}$ Annual PM Seminars, September / October 1997).

[6o] B. J. Pine II \& K. C. Korn. Infinite Possibility: Creating Customer Value on the Digita Frontier, 2011, Berrett-Koehle Publishers.

[61] P. T. Breen \& W. G. Scott. "Virtual Reality Applications in T\&D Engineering" $\left[39^{\text {th }}\right.$ Annual Rural Electric Power Conference 1995 January 1995, Paper 95 B5, pag- es 1-6]

[62] J. W. Baker. Saving Time \& Money: A Case Study of a Texas Utility's Experience Utilizing a Customized Factory-Built Subtation Approach for its Standard Outdoor Open-Air Distribution Substation, in: Proceedings of the $49^{\text {th }}$ Annual Transmission and Substation Design and $O p$ eration Symposium 2016 (TSDOS 2016], pages 182-199, 2016.

[63] M. Minelli \& H. Harkonen “"Working in the Third Dimension: Exploring 3-D Design Techniques or Electrical Substations" (Transmission \& Distribution Electricity Today Magazine, July
/ August 2014, pages 16-21].

[64] M. Trunko. "Standardized, 50-yrold substation construction still cuts costs today" (Electrical World Magazine, June 1997 pages 28-30].

[65] F. Léonard, P. Lembo \& G. Côté. "Computer Assisted Design [CAD-3D)" (Proceedings of CIGRE Canada Conference on Power Systems 2007, August 2007, Paper 438, pages 1-2].

[66] S. Ichihara, T. Kobayashi, M. Yoshida, R. Shinohara \& T. Saida. "Improvement in Substation Design and Construction through Application of $3 \mathrm{D}$ Modelling" (Proceedings of the CIGRE Session 2018, August 2018, Paper B3-214, pages 1-8].

[67] J. Baena, A. Cárdenas \& E. Poveda. BIM and its Application in the Design of High and ExtraHigh Voltage Electrical Substations, in: Proceedings of the $51^{-1}$ Annual Transmission and Substation Design and Operation Symposium 2018 (TSDOS 2018), pages 1-16, 2018

[68] W. Eyrich. Building Information Modeling (BIM] Technology in Substation Construction Progress Visualization - BIM 4D, in Proceedings of the $50^{\text {th }}$ Annual Transmission and Substation Design and Operation Symposium 2017 [TSDOS 2017), pages 277-283, 2017.

[69] M. McVey. Instruction Manuals and Training for Air-Insulated Substations, in: T. Krieg \& J. Finn, eds. CIGRE SC B3: Substations, Springer, chapter 14 , pages 343 357, 2019.

[70] J. Tuman Jr. \& G. G. Siegler. Innovative techniques in train ing and development of project management personnel" (Proceedings of the $12^{\text {th }}$ Annual PM Seminars, 1980)

[71] A. Saunders. "The Changing Utility Workforce and the Emergence of Building Information Modeling in Utilities" (Proceedings of CIGRE Canada Conference on Power Systems 2010, October 2010, Paper 106, pages 1-3).

[72] D. Milks \& T. Scullion. "Automation of Substation Design" (Proceedings of CIGRE Canada Conference on Power Systems 2010, October 2010, Paper 125 pages 1-7).

[73] S. Heuser, W. Eyrich \& M. Kokoruš. "Smart substation information model - challenges in the development of a Building Information Modeling (BIM) based software for substation design" (Proceedings of CIGRE International Colloquium "Building smarter substations", November 2016, Paper 106, pages 1-12) 